\title{
GOVERNO DO ESTADO E DESCENTRALIZAÇÃO DO PROGRAMA SEGUNDO TEMPO ${ }^{1}$
}

\author{
Edmilson Santos Santos \\ Universidade Federal do Vale do São Francisco, Petrolina, Pernambuco, Brasil
}

\begin{abstract}
Resumo
Este estudo de recorte descritivo buscou analisar a participação dos governos estaduais na difusão do Programa Segundo Tempo (PST) do Ministério do Esporte no intervalo de 10 anos (2003 a 2012). Os incentivos à descentralização do programa não foram suficientes para garantir maior participação dos governos estaduais em sua implementação. Após dez anos não foi possível capturar uma cultura institucional que permita garantir efeitos redistributivos e de diminuição das desigualdades regionais de acesso ao esporte educacional através do PST.
\end{abstract}

Palavras chave: Políticas públicas. Esporte educacional. Implementação.

\section{Introdução}

A política pública na área social tem como premissa básica a democratização do acesso a um determinado bem social, de forma a diminuir a desigualdade existente em sua distribuição na sociedade. Essa preocupação está expressa de maneira explícita no Programa Segundo Tempo do Ministério do Esporte.

Nesse sentido, o programa se coloca como um forte aliado na diminuição da desigualdade social. Por outro lado, a preferência alocativa está diretamente associada ao aumento de investimentos nas áreas em que se encontra o público-alvo do programa, as localidades e as regiões mais pobres ${ }^{2}$, que, historicamente, são portadoras de múltiplas desvantagens e severas assimetrias; dentre elas está o acesso à prática esportiva. $\mathrm{O}$ modelo de atuação do Estado brasileiro impõe algumas questões à produção da política pública que respondem às características de nosso federalismo ${ }^{3}$.

Apesar de ser uma área em que há disputas sobre a melhor forma de representá-lo, é possível assumir (sem grandes pretensões, pois o estudo aqui não é sobre o federalismo) o entendimento trazido por Soares (1998), de que ele é um sistema de organização territorial do poder entre o governo central e as entidades subnacionais interdependentes (governo estadual e prefeitura) e com relativa autonomia, cujo grau é determinante à compreensão da utilização dos recursos (podendo ser de poder, de tarefas e/ou financeiro) ${ }^{4}$.

O Brasil já experimentou uma variedade de arranjos federativos, como aponta Souza (2005). Mais do que compreender esse histórico, a questão que se coloca é tentar identificar que variáveis caracterizam o modelo brasileiro e seus impactos na distribuição de recursos. As assimetrias entre os níveis de governo (desempenho fiscal, por exemplo) produzem diferentes

\footnotetext{
${ }^{1}$ Pesquisa financiada pela Fundação de Amparo a Pesquisa do estado de Pernambuco.

${ }^{2}$ Rezende (1997) analisa o impacto das preferências alocativas nos gastos públicos e na descentralização.

${ }^{3}$ De uma forma bastante simplificada, podemos dizer que federalismo é um sistema de poder no qual governos autônomos, dentro de uma mesma área geográfica, cooperam para garantir unidade.

${ }^{4}$ Rodden (2005) desvincula o debate sobre o federalismo de seu viés fiscal e o identifica como um processo estruturado por instituições que distribuem e redistribuem autoridade.
} 
cenários à distribuição e redistribuição de recursos e à oferta de políticas públicas (GIBSON, CALVO, FALLETI, 2003) ${ }^{5}$.

Cada política engendra um tipo de relação entre os entes federados [que, no caso brasileiro, envolve uma complexidade a mais por conta da tripla soberania (ARRETCHE, 2005)], que produz significado e conteúdo distintos, com diferentes resultados para a política pública $^{6}$, seja pela descentralização política e autonomia de agenda, seja pela transferência fiscal e capacidade de arrecadação.

A desigualdade socioeconômica é o ponto de partida para o debate federalista brasileiro, e sua diminuição é o projeto a ser perseguido pelo Estado. A Constituição de 1988 colocou como objetivo para o fortalecimento da federação a promoção de um maior equilíbrio entre os entes constitutivos (SOUZA, 2005). Há uma tensão permanente no estado federativo pela distribuição/redistribuição de poder e de recursos que não estão associados à eficiência dos governos subnacionais. Dinâmicas de cooperação, disputas, consentimento e barganhas são produtoras de uma complexa engenharia política (ALMEIDA, 1995; RODDEN, 2005; SOUZA, 2005). Esse cenário aponta para relações intergovernamentais altamente competitivas, vertical e horizontalmente (SOUZA 2005).

Outra marca de nosso federalismo é sua descentralização convivendo ao lado de tendências centralizadoras (ALMEIDA, 2005). A Constituição de 1988, de forte viés municipalista - aspecto descentralizador -, transferiu capacidade decisória, funções e recursos às instâncias subnacionais. Os estados não foram os maiores beneficiários desse movimento, mas sim os municípios. Havia uma expectativa de que a descentralização melhoraria o resultado da política pública de forma a diminuir as desigualdades intrarregional (BARACHO, 2000).

No plano nacional, a crise do regime militar e a transição democrática geraram poderosas correntes descentralizadoras que foram associadas à democracia, à cidadania e à diminuição das desigualdades (ALMEIDA, 1995; ARRETCHE, 2005). No plano internacional, pressionada por uma maior eficiência dos governos, a descentralização estava associada ao paradigma da modernização gerencial (MELO, 1996). Esses dois movimentos acabaram por dar força a essa ideia, que acabou por criar dificuldades ao discurso e à prática centralizadora, elevando os custos da recentralização.

Porém, a consequência não esperada do processo de descentralização brasileira acabou por desnudar seus limites, principalmente aqueles associados à manutenção, ou aprofundamento, da desigualdade regional. São eles: a ambiguidade de competências entre as três esferas de governo, que produziu, em determinadas áreas, imobilismo; a baixa qualificação da burocracia; uma descentralização fiscal que dificultou a coordenação de certas políticas, de forma a garantir maior equidade ${ }^{7}$ entre os entes federativos; e, vulnerável às pressões advindas das elites locais, o clientelismo (MELO, 1996). O resultado mais drástico de todo esse processo foi a fraca coordenação entre os entes federados e a manutenção dos parâmetros de desigualdade (SOUZA, 2001;ARRETCHE, 2007). Affonso (1996) não interpreta a descoordenação como uma variável interveniente na manutenção do cenário de desigualdade, mas como uma característica do modelo de descentralização brasileira que produz resultados políticos desiguais.

Uma análise mais acurada do desempenho dos governos é dependente dos arranjos institucionais e setoriais de uma dada política (ARRETCHE, 2003; ALMEIDA, 2005). A

\footnotetext{
${ }^{5}$ A experiência internacional aponta que as clivagens étnicas e religiosas, produtoras de desigualdades, têm sido uma das principais preocupações na constituição do federalismo. No Brasil, segundo Arretche (2010), é a clivagem econômica que melhor explica as variações de nosso federalismo.

${ }^{6}$ Eles podem significar diversidade, diferença por concorrência ou desigualdade conforme o modelo analítico utilizado (ARRETCHE, 2010).

${ }^{7}$ A equidade aqui é interpretada nos termos propostos por Rawls (1992).
} 
complexidade das relações federativas interage com diferentes fenômenos e produz resultados diferenciados na distribuição das políticas públicas. Temos assistido, pelo menos em termos de políticas de esporte, cada vez mais, ao protagonismo do governo federal na formulação de políticas públicas (efeito centralizador), que se tornam mais e mais necessárias diante da falta de recurso dos governos subnacionais, dos (não) ganhos eleitorais que uma política que congrega esporte e criança podem ensejar ${ }^{8}$, da diferenciação do valor que a política de esporte para criança tem em cada agenda intergovernamental e da capacidade financeira, principalmente dos municípios dependentes das transferências constitucionais.

O governo federal pode promover determinadas políticas criando incentivos à cooperação entre os entes federados. A cooperação pode se dar por meio da produção de um pacote de incentivos de forma a seduzir ou mobilizar a atenção dos governos subnacionais, principalmente para aqueles com menor capacidade fiscal, menor capacidade de investimento. Porém, um conjunto de variáveis intermediárias que se coloca entre o governo federal e o beneficiário do programa produz dinâmicas diferenciadas na implementação da política pública.

Após experimentar 10 anos de implementação do Programa Segundo Tempo (2003 a 2012), torna-se importante analisar as consequências do modelo desenhado de descentralização das ações pelo Ministério do Esporte na diminuição das desigualdades regionais de acesso a esse bem social no que tange a participação dos estados. A implementação do PST segue o modelo de descentralização por demanda (é dependente de convênios com parceiros). Para sua implementação, o Ministério do Esporte elaborou um pacote de incentivos à descentralização que, dependendo das condições do parceiro, pode chegar a um subsídio de $100 \%$ do valor do projeto. No entanto, ele é dependente do desejo de cooperação intergovernamental dessa política. A grande questão é se esse modelo de descentralização por demanda é suficiente para se obter resultados redistributivos (atender a regiões mais vulneráveis interestadal ou intraestadual), principalmente diante da autonomia política, das instituições estaduais responsáveis com a implementação, das dificuldades operacionais à descentralização e dos patamares existentes de políticas locais de democratização do esporte, viés competitivo.

\section{Método}

O trabalho teve por objetivo verificar o comportamento dos estados na descentralização do Programa Segundo Tempo, nos convênios realizados entre 2003 a 2012. Diferente da adesão dos municípios, os estados podem coordenar a descentralização de forma a implementar o PST, prioritariamente, junto aos municípios mais vulneráveis (efeito redistributivo). Portanto, a unidade de análise do desempenho será o município.

As informações referentes ao Programa Segundo Tempo foram coletados diretamente no site do programa no Ministério do Esporte; o grau de vulnerabilidade no interior dos estados foi produzido com base no Índice de Exclusão Social (POCHMANN e AMORIM, 2003) ${ }^{9}$; sobre as prefeituras, diretamente do site do Instituto Brasileiro de Geografia e Estatística - IBGE. O Distrito Federal foi excluído da análise por não possuir o terceiro ente federal, a unidade municipal.

\footnotetext{
${ }^{8}$ Para análise da participação dos partidos e coalizões na difusão do PST, ver Santos (2012).

${ }^{9}$ Para efeito deste trabalho, estamos considerando que os municípios mais vulneráveis são aqueles estão no nível mais elevado de exclusão do Índice de Exclusão Social (IES) de Pochmann e Amorim (2003). São quatro os níveis de exclusão social, o mais alto, Exclusão Severa (ES), Alta Exclusão (AE), Média Exclusão (ME) e Baixa Exclusão (BE).
} 


\section{Resultados}

Como pode ser observado no gráfico abaixo, a descentralização do PST pelos governos estaduais apresenta três cenários. Primeiro, sem que com isso represente uma escala valorativa, aparecem as regiões onde todos os estados aderiam ao programa, caso do Sul e Centro-Oeste. Depois, as regiões Norte e Nordeste onde apenas um estado em cada uma não aderiu ao programa. Por último, o Sudeste em que somente a metade dos estados conveniou com o Ministério do Esporte para fazer a implementação do programa, como pode ser observado no gráfico 1.

Gráfico 1: Adesão dos governos estaduais ao PST de 2003 a

2012

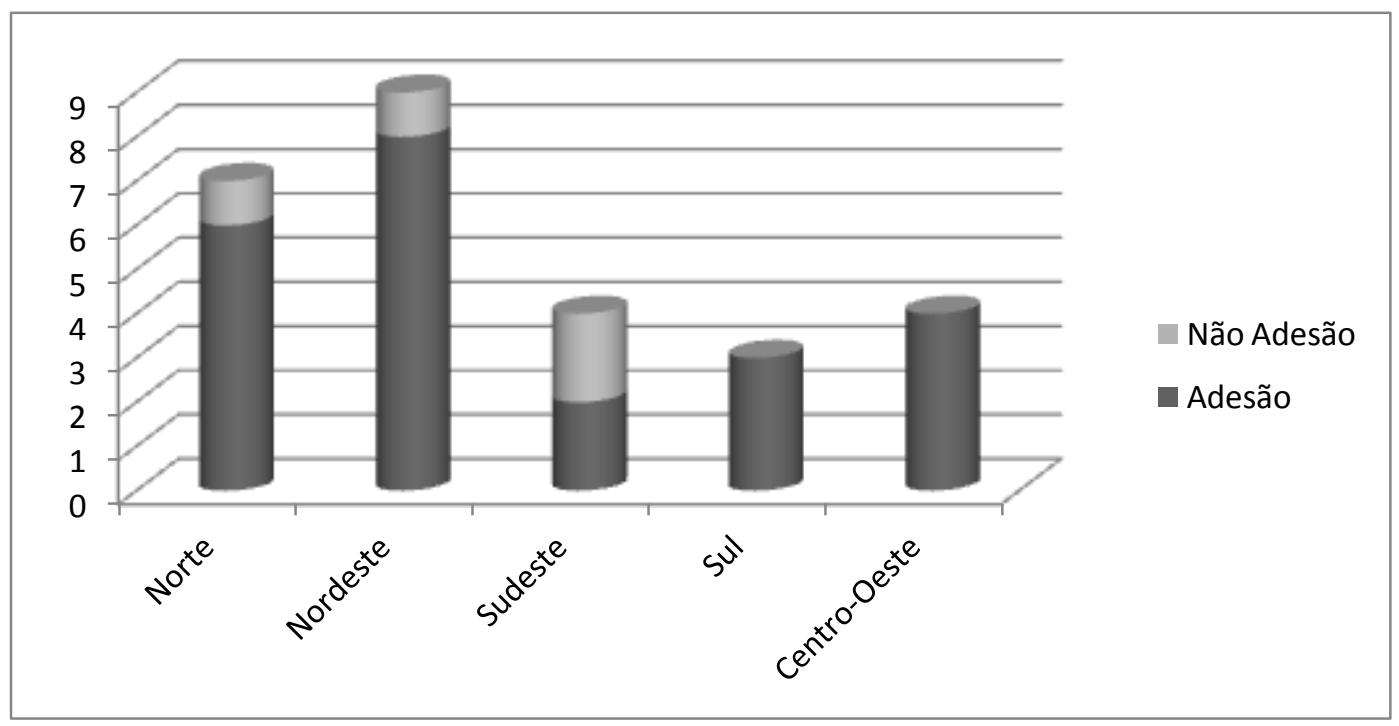

Fonte: Dados do Ministério do Esporte (2013).

Durante os dez anos de implementação, apenas quatro estados não aderiam ao PST: Roraima, Maranhão, São Paulo e Espírito Santo. A primeira vista, não há um padrão desse não desejo de adesão. Os estados apresentam características muito díspares do ponto de vista econômico e social. Do ponto de vista institucional, todos possuem um órgão que é responsável pela política pública de esporte de forma exclusiva ou compondo com outra secretaria. Talvez não seja possível encontrar uma variável que explique a não adesão dos quatro estados. É bem provável que para cada um deles um conjunto de variáveis interferiu de maneira bastante particular na configuração dessa realidade.

Diante da autonomia dos estados à adesão ao PST ou à implementação de políticas próprias de esporte educacional, não é possível afirmar que esses estados patrocinaram a exclusão das crianças vulneráveis a esse bem, objetivo do programa. Por exemplo, a atuação concorrencial do governo de São Paulo pode ser explicada por dois motivos: capacidade de financiamento para produzir política visando a sua própria agenda no terreno do esporte educacional e concorrência política pela melhor política como forma de distinção de desempenho político.

A participação de cada um dos estados na difusão do programa em direção aos municípios seguiu uma lógica bastante própria. Conforme tabela 1, chama atenção o fato de apenas um estado conseguir, ao longo de dez anos, garantir acesso ao programa de todos os seus municípios, mesmo que corresponda a apenas uma adesão. Os resultados do Amapá e do Acre também foram bastante expressivos. Na outra extremidade, temos seis estados que conseguiram levar o PST a menos $10 \%$ de seus municípios. Não é possível identificar um 
padrão regional, nem é possível associar ao nível de desenvolvimento dos estados, haja vista as colocações do Rio de Janeiro $\left(16^{\circ}\right)$ e do Rio Grande do Sul $\left(18^{\circ}\right)$; nem pelo tamanho do estado, Amapá $\left(2^{\circ}\right)$ e Rondônia $\left(21^{\circ}\right)$. A descentralização promovida pelos estados em direção aos seus municípios não apresenta um padrão claro. Resultado compatível com nosso modelo federalista.

Tabela 1: Percentual de municípios que receberam o PST pelos órgãos estaduais

\begin{tabular}{|c|c|r|c|c|c|r|r|}
\hline Clas. & Estado & no mun. & $\%$ & Clas. & Estado & nº mun. & $\%$ \\
\hline 1 & CE & 184 & 100 & 12 & AL & 102 & 27,45 \\
\hline 2 & $\mathrm{AP}$ & 16 & 93,75 & 13 & $\mathrm{SC}$ & 295 & 22,18 \\
\hline 3 & $\mathrm{AC}$ & 22 & 90,91 & 14 & $\mathrm{AM}$ & 62 & 20,97 \\
\hline 4 & $\mathrm{MS}$ & 79 & 75,64 & 15 & $\mathrm{TO}$ & 139 & 17,99 \\
\hline 5 & $\mathrm{MT}$ & 141 & 73,05 & 16 & $\mathrm{RJ}$ & 92 & 13,04 \\
\hline 6 & $\mathrm{PI}$ & 224 & 49,11 & 17 & $\mathrm{BA}$ & 417 & 6,95 \\
\hline 7 & $\mathrm{PR}$ & 399 & 41,75 & 18 & $\mathrm{RS}$ & 497 & 5,44 \\
\hline 8 & $\mathrm{PE}$ & 185 & 41,62 & 19 & $\mathrm{RN}$ & 167 & 3,59 \\
\hline 9 & $\mathrm{GO}$ & 246 & 40,65 & 20 & $\mathrm{PA}$ & 144 & 2,8 \\
\hline 10 & $\mathrm{MG}$ & 853 & 39,16 & 21 & $\mathrm{RO}$ & 52 & 1,92 \\
\hline 11 & $\mathrm{SE}$ & 75 & 37,33 & 22 & $\mathrm{~PB}$ & 223 & 0,9 \\
\hline
\end{tabular}

Fonte: Programa Segundo Tempo/Ministério do Esporte (2013).

Diferentemente dos municípios que não têm como coordenar uma ação redistributiva, no plano regional, os estados, através da forma como coordenam a distribuição do programa entre os municípios, possuem ferramentas para imprimir uma gestão redistributiva do PST, levando prioritariamente aos municípios mais vulneráveis ou distributiva, como experimentado pelo Ceará $(\mathrm{n}=174)$.

Chama atenção o fato de alguns estados com números muito reduzidos de municípios vulneráveis não terem, em dez anos, conseguido levar o programa até eles, conforme tabela 2. É o caso do Rio de Janeiro $(\mathrm{n}=1)$ e Santa Catarina $(\mathrm{n}=2)$. Porém, ao lado desses estados estão também aqueles que possuem elevado número de municípios no estágio de Exclusão Severa $(E S)$ [Maranhão $(\mathrm{n}=142)$ e Paraíba $(\mathrm{n}=209)$ ] e que também não tiveram acesso ao programa.

Não podemos dizer que é apenas um problema de gestão dos estados, pois o programa não apresenta incentivos suficientes ou adequados à cooperação. $\mathrm{O}$ governo central também não imprimiu condicionalidades no programa de forma a induzir os estados a promoverem difusão em direção aos municípios de maior exclusão (ES). Por outro lado, não podemos esquecer que a inação é uma das formas de traduzir determinados interesses políticos e produzir uma política pública (SECCHI, 2013), pois a política pública é tudo aquilo que o governo faz ou deixa de fazer.

Tabela 2: Percentual de municípios em exclusão severa que receberam o PST pelos estados.

\begin{tabular}{|c|c|c|c|c|c|}
\hline Estado & no mun/ES & $\%$ & Estado & $\begin{array}{c}\mathrm{n}^{\circ} \\
\text { mun/ES }\end{array}$ & $\%$ \\
\hline $\mathrm{CE}$ & 174 & 100 & $\mathrm{TO}$ & 101 & 13,86 \\
\hline $\mathrm{AC}$ & 21 & 90,48 & $\mathrm{BA}$ & 369 & 6,23 \\
\hline $\mathrm{AP}$ & 10 & 90 & $\mathrm{PA}$ & 109 & 0,92 \\
\hline $\mathrm{MS}$ & 8 & 75 & $\mathrm{MA}$ & 212 & 0 \\
\hline $\mathrm{MT}$ & 12 & 58,33 & $\mathrm{SP}$ & 4 & 0 \\
\hline $\mathrm{MG}$ & 229 & 51,97 & $\mathrm{RO}$ & 4 & 0 \\
\hline $\mathrm{PI}$ & 213 & 48,83 & $\mathrm{~PB}$ & 209 & 0 \\
\hline $\mathrm{SE}$ & 68 & 38,24 & $\mathrm{RN}$ & 142 & 0 \\
\hline $\mathrm{PE}$ & 168 & 37,5 & $\mathrm{RJ}$ & 1 & 0 \\
\hline
\end{tabular}




\begin{tabular}{|c|c|c|c|c|c|}
\hline $\mathrm{AL}$ & 97 & 24,74 & $\mathrm{RS}$ & 5 & 0 \\
\hline $\mathrm{GO}$ & 25 & 24 & $\mathrm{SC}$ & 2 & 0 \\
\hline $\mathrm{PR}$ & 29 & 20,69 & $\mathrm{RR}$ & 13 & 0 \\
\hline $\mathrm{AM}$ & 60 & 18,33 & $\mathrm{ES}$ & 5 & 0 \\
\hline
\end{tabular}

Fonte: Programa Segundo Tempo/Ministério do Esporte (2013); o nível de exclusão social Pochmann e Amorim (2003).

Contrastar o desempenho dos estados na difusão do PST em direção aos municípios menos vulneráveis (BE) torna-se importante para melhor compreender a cultura institucional que está sendo produzida pelo programa. A distribuição dos municípios menos vulneráveis não é equilibrada entre as regiões, como pode ser observado no gráfico 1. As regiões Sudeste e Sul monopolizam a incidência de municípios de baixa exclusão (97\%) e a região Norte não possui municípios nesse nível de exclusão. Portanto, as regiões Sudeste e Sul são menos dependentes de ações que promovam a equidade ao serviço (esporte educacional) e as regiões Norte e Nordeste, mais dependentes.

Gráfico 1. Percentual de municípios menos vulneráveis por região

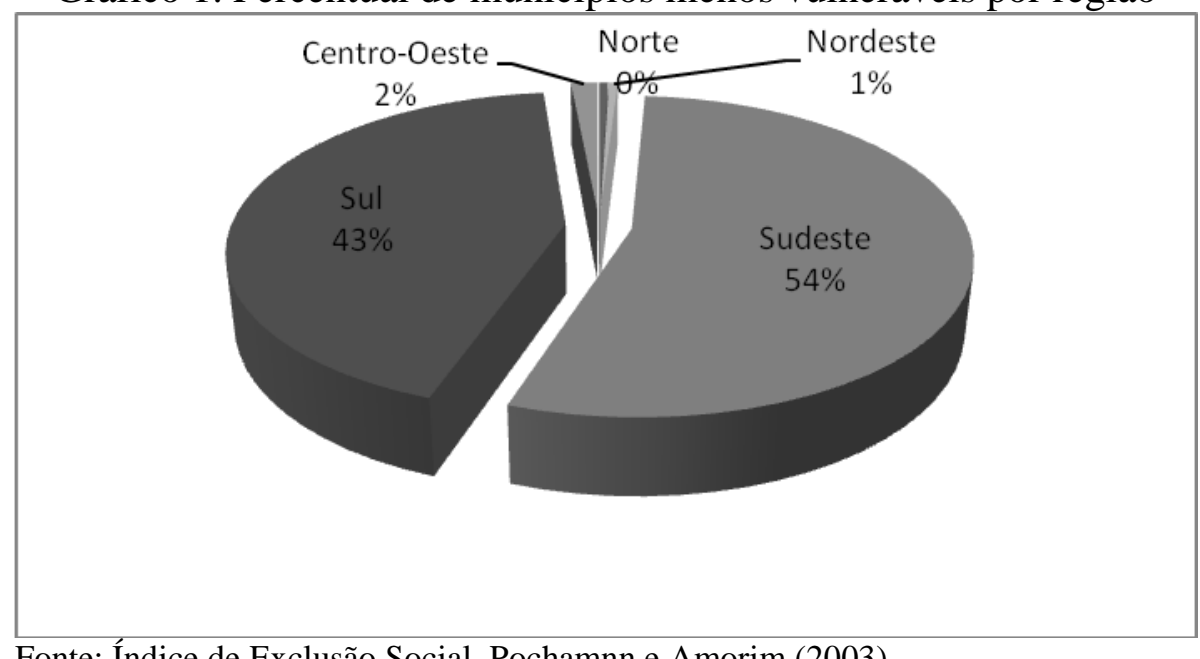

Fonte: Índice de Exclusão Social, Pochamnn e Amorim (2003)

A tabela 4 mostra, dentre os estados que aderiam ao PST, o desempenho de cada um em levar o programa até os municípios menos vulneráveis. O que chama atenção é que todos os estados conseguiram melhores percentuais de difusão do programa junto aos municípios menos vulneráveis do que aos mais vulneráveis. Isto não significa que beneficiários menos vulneráveis não possam estar recebendo o programa, pois nos municípios menos vulneráveis também encontramos bolsões de miséria e exclusão. Porém, não é isto que estamos analisando aqui. A questão é o papel estratégico do estado de coordenar ações de forma a levar o programa aos municípios menos vulneráveis, unidade de análise escolhida para interpretar os resultados do programa. São eles, por um conjunto de questões, que são mais dependentes da descentralização de recursos para produzirem políticas públicas. No entanto, a realidade do Rio de Janeiro é emblemática e marcada pelo contraste. Possui um município em ES, o pior nível de exclusão, e não conseguiu levar o programa até lá. Já o seu desempenho em direção aos municípios menos vulneráveis (BE) foi de $40 \%$. Isto indica que os estados imprimiram ação de forma a fazer uma descentralização que amplifica a desigualdade. 
Tabela 4. Descentralização do PST entre os estados que possuem municípios com baixa exclusão

\begin{tabular}{|l|c|c|c|}
\hline \multicolumn{1}{|c|}{ Estado } & Mun. BE & PST & $\%$ \\
\hline Tocantins & 1 & 1 & 100 \\
\hline Pernambuco & 1 & 1 & 100 \\
\hline $\begin{array}{l}\text { Mato Grosso do } \\
\text { Sul }\end{array}$ & 1 & 1 & 100 \\
\hline Goiás & 2 & 1 & 50 \\
\hline Espírito Santo & 1 & 0 & 0 \\
\hline Rio de Janeiro & 5 & 2 & 40 \\
\hline Paraná & 7 & 3 & 42,9 \\
\hline Minas Gerais & 9 & 5 & 55,6 \\
\hline Santa Catarina & 26 & 3 & 11,5 \\
\hline Rio Grande do Sul & 53 & 2 & 3,8 \\
\hline São Paulo & 93 & 0 & 0 \\
\hline
\end{tabular}

Fonte: Programa Segundo Tempo/Ministério do Esporte (2013); nível de exclusão social Pochmann e Amorim (2003).

Não podemos deixar de considerar, a partir dos dados aqui apresentados, que o gestor pode estar atuando de forma a maximizar sua imagem diante dos municípios em que o custo de implementação pode ser menor. Municípios mais vulneráveis, geralmente dependentes das transferências constitucionais, apresentam maior custo de implementação das políticas públicas.

Analisando o número de municípios vulneráveis e percentual desses que receberam algum núcleo do PST via governo estadual, não é possível estabelecer alguma relação entre região, tamanho do estado (população) e nível de desenvolvimento. Porém, não escapa à analise o fato de haver, do ponto de vista percentual, melhor desempenho entre os municípios menos vulneráveis do que nos mais vulneráveis. Esse resultado aponta, para os objetivos estabelecidos pelo programa, uma distorção alocativa.

\section{Considerações Finais}

A experiência dos 10 anos de implementação do PST indica que os incentivos ofertados pelo programa não são suficientes para promoverem adesão de $100 \%$ dos governos estaduais na difusão do programa. Porém, não podemos deixar de destacar, isto não significa que os possíveis beneficiários não possam estar sendo atendidos por programas similares formulados pelos governos estaduais. Esse resultado vai na direção do que é suportado pelo nosso modelo de federalismo, concorrência vertical tende a produzir resultados diferenciados.

Essa primeira observação aponta que para os governos estaduais se tornem parceiros estratégicos do Ministério do Esporte na difusão do Programa Segundo Tempo, principalmente objetivando efeito redistributivo, é preciso revisar o sistema de incentivos à descentralização para esse ente governamental. Do contrário, permaneceremos produzindo uma desigualdade regional que compromete o princípio da justiça social almejada pelos programas sociais do ministério.

Do ponto de vista intraestadual, os governos estaduais têm autoridade para imprimir um movimento redistributivo levando, de forma prioritária, o programa aqueles municípios mais vulneráveis. Essa não foi a realidade para muitos estados cujo resultado do programa reproduziu o status quo. Apenas $30 \%$ dos municípios em ES conseguiram receber o programa via governo estadual no período aqui analisado. 
O melhor desempenho entre as regiões foi com a região Sudeste, considerando aqueles estados que conveniaram com o governo federal. Apesar de terem o menor número de municípios em ES, obtiveram uma descentralização de $51,7 \%$. A pior região foi a Sul com apenas $16,6 \%$. A região Nordeste ficou com $28,8 \%$ e Centro-Oeste, $24,7 \%$. O que podemos perceber é que o programa não ajudou a diminuir a desigualdade regional na oferta do esporte educacional. Essa assertiva se confirma quando analisamos o resultado da distribuição do programa entre os municípios menos vulneráveis pelos governos estaduais.

Podemos considerar, a partir das análises aqui realizadas, que governos estaduais não se constituíram como parceiros estratégicos do governo com objetivo de diminuir as desigualdades na oferta do Programa Segundo Tempo.

\title{
STATE GOVERNMENT AND DECENTRALIZATION OF SEGUNDO TEMPO PROGRAM
}

\begin{abstract}
This descriptive study investigates crop the participation of state government in decentralization Segundo Tempo Program (PST) in 10-year interval (2003-2012) in reducing regional inequality offering sport education. Incentives for decentralization program were not sufficient to ensure greater involvement of state governments in their dissemination. After ten years it was not possible to capture an institutional culture that will guarantee redistributive effects and reducing regional inequalities in access to sport education by PST.
\end{abstract}

Keywords: Public policy. Education sport. Implementation.

\section{GOBIERNO DEL ESTADO Y LA DESCENTRALIZACIÓN DEL PROGRAMA TEMPO SEGUNDO}

\section{Resumen}

Este estudio descriptivo investiga la participación de los gobiernos estatales en la descentralización del Programa Segundo Tempo de Ministerio de Deportes al intervalo de 10 años (2003-2012). Incentivos para programa de descentralización no fueron suficientes para garantizar una mayor participación de los gobiernos estatales en su implementación. Después de diez años no fue posible capturar una cultura institucional que asegure efectos redistributivos y la reducción de las desigualdades regionales en el acceso al deporte educativo a través del PST.

Palabras clave: Política pública. Deportes educativos. Implementación.

\section{Referências}

AFONSO, J. R. R.; LOBO, T. Descentralização fiscal e participação em experiências democráticas retardatárias. Planejamento e Políticas Públicas, Brasília, n. 14, p. 3-36, 1996.

ALMEIDA, M. H. T. Federalismo e políticas sociais. Revista Brasileira de Ciências Sociais, São Paulo, v. 10, n. 28, p. 88-108, 1995.

ALMEIDA, M. H. T. Recentralizando a federação? Revista Sociologia e Política, Curitiba, v. 24, p. 29-40, jun. 2005.

ARRETCHE, M. Dossiê agenda de pesquisa em políticas públicas. Revista Brasileira de Ciências Sociais, São Paulo, v. 18, n. 51, 7-9, fev. 2003.

ARRETCHE, M. Quem taxa e quem gasta: a barganha federativa na federação brasileira. Revista de Sociologia Política, Curitiba, n. 24, p. 69-85, jun. 2005. 
ARRETCHE, M. A agenda institucional. Revista Brasileira de Ciências Sociais, São Paulo, v. 22, n. 64, p. 148-151, 2007.

ARRETCHE, M. Federalismo e igualdade territorial: uma contradição em termos? Dados, Rio de Janeiro, v. 53, n. 3, p. 587-620, 2010.

BARACHO, M. A. P. A importância da gestão de contas públicas municipais sob a premissa da governance e accountability. Revista do Tribunal de Contas do Estado de Minas Gerais, v. 34, n. 1, p. 129-161, jan./mar. 2000.

GIBSON, E. L.; CALVO, E. F.; FALLETI, T. G. Federalismo realocativo: sobrerepresentação legislativa e gastos públicos no hemisfério ocidental. Opinião Pública, Campinas, v. 9, n. 1, p. 98-123, 2003.

MELO, M. A. Crise federativa, guerra fiscal e "hobbesianismo municipal" efeitos perversos da descentralização? São Paulo em Perspectiva, São Paulo, n. 10, v. 3, p. 11-20, 1996.

POCHMANN, M.; AMORIM, R. (Orgs.) Atlas da exclusão social no Brasil, Volume 1. São Paulo: Cortez, 2003.

RAWLS, J. Justiça como equidade: uma concepção política, não metafísica. Lua Nova, São Paulo, n. 25, p. 25-29, 1992.

REZENDE, F. C. Descentralização, gastos públicos e preferências alocativas dos governos locais no Brasil. Dados, Rio de Janeiro, v. 40, n. 3, p. 413-440, 1997.

RIBEIRO, L.C.Q. et al. Níveis de integração dos municípios brasileiros em Rms, RIDEs e AUs à dinâmica da metropolização. Observatório das Metrópoles, 2012.

RODDEN, J. Federalismo e descentralização em perspectiva comparada: sobre significados e medidas. Revista Sociologia e Política, Curitiba, v. 24, p. 9-27, jun. 2005.

SECCHI, L. Políticas públicas: conceitos, esquemas de análise, casos práticos. São Paulo: Cengage Learmimg, 2003.

SOARES, Márcia Miranda. Federação, democracia e instituições políticas. Lua Nova, São Paulo, n. 44, p. 137-163, 1998.

SOUZA, C. Federalismo e gasto social no Brasil: tensões e tendências. Lua Nova, São Paulo, n. 52, p. 5-28, 2001.

SOUZA, C. Federalismo, desenho constitucional e instituições federativas no Brasil Pós1998. Revista Sociologia e Política, Curitiba, v. 24, p. 105-121, jun. 2005.

Recebido em: 12/12/2015

Revisado em: 11/04/2016

Aprovado em: 27/05/2016

Endereço para correspondência:

edmilson.santos@univasf.edu.br 
Edmilson Santos Santos

Universidade Federal do Vale do São Francisco

Avenida José de Sá Maniçoba, s/n

Campo Universitário

56304-917 - Petrolina, PE - Brasil 